\title{
A relational society
}

\section{Michael Rustin}

\section{Human relationships cannot be encompassed within a narrow, market-exchange world view.}

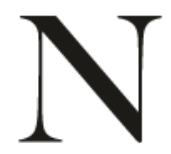
eoliberalism has as one of its basic presuppositions the idea that the human world is composed essentially of individuals, who should as far as possible be free to make their own choices and to advance their own interests, in pursuit of whatever they may deem their happiness to be. To be sure, individuals are expected to avoid interfering with the freedom of others, and systems of moral and legal regulation exist to ensure that such limits and protections are enforced. But these are seen as applying to what are essentially individuals, acting without reference to a wider social context.

In reality, of course, individuals do not pursue their interests in isolation from, or even in negotiated contractual exchanges with, one another; they do so within large and complex economic and governmental systems, which generally have far more influence on their opportunities and chances in life than the personal decisions they make. The capacity to formulate desires and aspirations, and the capabilities to advance them, are substantially shaped by individuals' conditions of birth and family origin, even in those societies which are most open to individuals' own strivings. Livelihoods (the essential means of life, and the grounds for being able to make choices and pursue goals) are usually made available to, or withheld from, people, by decisions taken within organisations of many kinds, such that the individual freedoms which the dominant order proclaims as its first principle are in fact mightily constrained by forces over which no individual has control - although of course some have more power than others.

But - beyond this - my argument is that the very idea of an autonomous, selfseeking individual as the foundational 'atom' of the human world is ill-conceived. 


\section{Soundings}

For human beings are essentially social beings - and individual freedom and choice, where they emerge and exist, are the outcome of delicate and precarious social arrangements, not primordial facts of nature. ${ }^{1}$ And a besetting fault - indeed pathology - of contemporary capitalist societies is that in their relentless advocacy of individual freedom, gratification and possessiveness, they undermine the very social conditions which make its exercise, for most people, possible. ${ }^{2}$

This essay is primarily concerned with the kinds of relationship with others on which individuals depend for their well-being, through the various phases of their lives. It focuses particularly on the quality of our social institutions - in the spheres, for example, of health, education, work, criminal justice or citizenship - and argues that their quality depends substantially on what qualities of human relationship they facilitate. A final section considers the effects of a narrowly instrumental world view on relationships between humankind and the material world.

\section{Human needs and the welfare state}

In the long arguments about what in one discourse is called the welfare state, in another social protection, and in another social rights and entitlements, a crucial demand has been for recognition of the realities of unavoidable and universal human dependency.

Human beings come into the world entirely helpless, and are dependent, for many years, on the care of others. Indeed, they are even dependent on their loving care, since the capacity of persons to develop minds and emotional resources depends on the quality of attention given to them through their infancy and childhood. Throughout their lives, but in particular in their later years, people are vulnerable to illness, and nearly all will experience a period of time when they are as intensely vulnerable and dependent upon the ministrations of others as they were when they were first born.

In complex, educated, industrial societies, our experiences of dependency and need are not confined to those that are, in a basic sense, given to us by our biology. Societies require individuals to achieve learning and development, take up roles and positions within them, and to survive social transitions (for example to and from school, into the world of work, to parenthood, to retirement) and sudden rupture in the pattern of their lives. These are expectations placed on individuals from 


\section{A relational society}

their earliest days of life, and where they are not, or cannot, be met, a repertoire of remedies and sanctions are invariably mobilised to bring about some acceptable level of compliance with social norms. (Different societies employ different regimes of compliance for their deviants, and these change with the times, as Michel Foucault among others has shown.)

When children first enter the world, they already bring with them complex material and relational needs, whose satisfaction or otherwise by their primary carers will always have lasting consequences for their later development and well-being. A child's entry into the world beyond his or her family, and into the different stages of education and the challenges which this brings, carries with it another cluster of needs, for the provision of which children and their families depend on others, in schools and other supportive social agencies. Later still, comes the transition for young people from being receivers of and participants in education, to the world of work, when individuals are expected to become the makers of goods and the producers of value in their own right. This transition involves its own vulnerabilities, which in present economic circumstances have become particularly acute, since for many young people work of any kind, and especially work which offers the prospects of personal satisfaction and development, are absent. Today, even the transition from university to employment, for the relatively privileged young people who have been to university, is often hazardous and full of anxiety, so defective has society become in its support of such crucial stages in the life-course.

Nor is the experience of becoming a parent to be understood as a merely 'natural' function, capable of being undertaken outside of a supportive network of social relations, including families, friendships and formal institutions. These include the medical services necessary to support the birth of a child, and the material arrangements which are necessary if a family is to have somewhere to live, and resources on which to live - which can no longer to be taken for granted given the deficiencies of contemporary housing and employment opportunities.

And later still, there is an inevitable transition from the world of work into retirement, and the experiences this can bring, which may range from the imposition of an abrupt loss of identity (which may amount to a kind of social death) to entry into a phase of post-retirement life which can have the potential both for new kinds of freedom and satisfaction, and for experiences of loneliness and emptiness.

The modern 'welfare system', for want of a better term, was constructed during 


\section{Soundings}

the earlier epoch of capitalism that we have called the social democratic settlement, as a set of responses to these various phases of dependency. This settlement recognised - and indeed insisted - that the 'law of the market' could not, for the majority of people, provide sufficiently for such needs.

One means of public intervention then chosen was material support, providing for the redistribution of money and resources to individuals and families at dependent phases of their life-cycle when these could not be adequately provided by individual self-provision (and of course this still, in somewhat attenuated form, continues to function). And although there was usually some element of redistribution between richer and poorer involved in these transactions, a much more important logic was redistribution between people at different phases of their life-cycle. That is, from those at a phase of life when they were able to support their families from their earnings in the labour market, to those who at another phase of life became excluded from it, for reasons of age, sickness, economic circumstances (local or more pervasive unemployment) or misfortune. One of the achievements of Peter Townsend's research on poverty was his demonstration that poverty was a condition which was and is suffered by large numbers of unexceptional individuals, at particular phases of their life-cycle, and was not merely the experience of a particular social class of the disadvantaged and the poor. ${ }^{3}$

Many forms of intervention in response to human needs are not, however, primarily material or financial in nature, but involve activities of nurturing, caring, educating, advising, nursing, rescuing and protecting. In the myriad of occupations devoted to these services (child care, medicine, teaching, nursing, social care, even policing) the primary work consists of responding in qualitatively specific ways to the needs of people, with the attention, commitments and skills which are appropriate to each particular situation. A diversity of capabilities and sensitivities are involved in all of these activities, each supported at best by distinct occupational cultures.

Today, the primary goals of these fields of work - namely to respond to needs arising from different kinds of vulnerability - are at risk of being pushed to the margin by the reframing of all organisational and personal tasks in terms of economic gain, market advantage and profit-seeking, as well as compliance with instructions and regulations that often have little relevance to the tasks in hand. One of the main reasons why there is such dismay and outrage in the public sector at the changes being imposed on it so ruthlessly at the present time is the belief of its workers that the principal value 


\section{A relational society}

and meaning of what they do goes unrecognised, disparaged and even abused by policy-makers and the managements that are made to serve as their instruments.

\section{How neoliberalism undermines social provision}

It is of course inevitable that in modern societies the services which provide for human vulnerabilities are organised within formal institutions. These are often highly complex organisations, sometimes involving sophisticated technical resources, as in medical care. For reasons of scale these are necessarily 'impersonal' in some of their operations. Resources are always necessarily limited, and impersonal procedures - for example the use of web-based systems to convey information or make appointments - may be time- and cost-saving to good effect. Good quality human services, even if they depend primarily on face-to-face interactions (such as between teacher and pupil or therapist and client) can neither be created nor maintained without education, training, planning and organisation. Difficult choices have to be made in deciding how to provide complex human services, in regard to which kind of institutions work best in which circumstances. There is no universal solution to be found to the question of what organisational forms can provide the optimal containers for each kind of service. What is, however, certain is that many different 'voices' and interests need to be involved in deciding democratically, and through public discussion, which institutional forms are best in what conditions.

Under the regime of neoliberalism, however, a single imposed 'universal model' for the provision of services is being propagated and enforced. This is based on the doctrine that services will be provided effectively and efficiently only where providers are motivated primarily by financial incentives, and the belief that the transfer of a hitherto public service to a private provider is ipso facto likely to lead to its improvement and to greater efficiency. This assumption is of course a false one, and one that often leads to a displacement of attention from the provision of the service, and the complex systems and cultures required to achieve this, to the shortterm aims of financial return. The gross scandals of A4E, the firm to whom the lion's share of the Preparation for Work programme was handed over, and of G4S, the company entrusted with providing security for the London Olympics, are examples of the risks involved in this approach.

This same logic now demands that provider organisations and their sub-units 


\section{Soundings}

operate as businesses or quasi-businesses, with the state of their balance-sheets given priority over all other indicators of their performance and value. Such 'market disciplines' have been widely imposed on institutions which are still formally 'public' in their ownership, ostensibly as means to improve their efficiency. But it is clear that the 'public' character of these institutions can be made into a mere external shell, which allows their internal remodelling into structures and cultures very close to those of corporate businesses.

Once this remodelling has taken place, it becomes only a further step to allow 'fully private' providers entry into what have been redefined as 'markets', and for the wholesale privatisation of public services to take place. This is a programme of privatisation by stealth and misrepresentation, since even as these organisational changes are enforced, public denials continue that they have anything to do with privatisation. And this the logic has also legitimated increasing inequalities of rewards to individuals within the public sector, with differentials between those in more and less senior positions increasing by multiples over recent years. One hardly has to be cynical to recognise that the tacit purpose of creating a stratum of supermanagers (e.g. university vice-chancellors, NHS and local authority executives, and their phalanxes of lieutenants) paid at something approaching the level of private sector managers is to weaken their identifications with public cultures and values, and to recruit them as accomplices to the new order of the rich.

The problem is that if organisations, their managers and their employees are incentivised chiefly to do what is in their own economic interests, the consequence is liable to be the invasion and corruption of their primary tasks and commitments. The 'economic' logic of maximising financial (or reputational) returns for an institution often runs counter to the 'needs-based' logic of fulfilling their professional and human goals. And what may well begin, for a senior public manager, as an external pressure on him or her to meet demands to achieve greater efficiency or solvency, over time may become an internalised commitment to financial goals. These now come to be perceived as the only reality that matters, in contradistinction to what they may now see as a merely sentimental or reactionary loyalty to professional client-oriented goals and methods. The seduction of high salaries comes to be not merely the material satisfactions they bring (and financial insurance against the omnipresent risk of failure and dismissal) but also the satisfactions of competing for status, prestige and power with other 'high earners', clearly a major motivation 


\section{A relational society}

among the elites of the private sector.

How do practitioners in such an institution decide between the priority they give to the perceived needs of its clients, and its own financial or reputational interest? Marketised systems provide strong incentives to cherry-pick and to cheat, to find ways of maximising economic returns while minimising the commitment of resources to the most needy. How much easier it is to demonstrate strong educational performance if one excludes weak pupils; or to achieve high returns in health care if one avoids taking on the most chronically vulnerable patients. Or to be a 'world class university' if only the most talented and privileged students are enrolled. This is not to mention the grosser forms of cheating which are sometimes revealed, as when payment is claimed for services which are not even delivered (as in the finding of jobs for young people in a recent case). The principles of responsiveness to the needs of others, and of pursuit of individual and institutional self-interest, are frequently in conflict with one another. A different set of assumptions and values is needed if this contradiction is to be resolved, and a proper priority accorded to human well-being.

Regulatory systems - which have become an increasingly pervasive aspect of modern forms of governance - often merely incentivise self-interested behaviour by institutions or their workers, even when their ostensible object is to ensure that they respond appropriately to people's needs. This is because compliance can become an overriding preoccupation within organisations, distracting practitioners from responsiveness to their primary task, rather than assisting them in it.

In all these ways, a neoliberal imposition of market relations undermines institutions originally set up in recognition of human need and social interdependence.

\section{Relationships and well-being}

The development of human potentialities and capabilities, and thus the potential both for individuals' fulfilment and for the production of social goods, depends essentially on the quality of relationships within which they are nurtured. This is obvious from everyday experience. We know that children do better, in terms of physical and emotional health, and educational development, the better the quality of early care that they receive. A measure of governmental acknowledgement of this truth is accorded by the provision of services in early years - it was the rationale for the now-diminishing Sure-Start programme. We know that children learn more in 


\section{Soundings}

school if they have more attention from teachers. This is why one of the benefits sought in the purchase of private education is smaller classes and more favourable pupil-teacher ratios. The universities of highest standing have more resources to spend, per student, than lower-ranked universities.

In entering paid work for the first time (or perhaps at any time) the finest gift any new entrant can receive is a supervisor, manager or mentor who has an interest in and a commitment to his or her well-being and development. It is a good fortune when someone's early occupational experience is of this kind, and it often makes a lasting difference to later career development and fulfilment. Furthermore, such qualities of concern, once experienced, are often internalised, and become part of a 'habitus' which is lived out in later practice, to the good of later entrants into a field or institution who benefit from a 'passing on' of the attention earlier given. Such good occupational practices, based on recognition of the importance of relationships for personal development, are not merely the attributes of individuals. They can be embodied in institutions and occupational cultures, over long periods, and may contribute a great deal to the reputation and success of a particular organisation or enterprise. Someone once told me, apropros of a particular young person entering her first permanent job, 'She is fortunate - that organisation (which my informant knew well) has a reputation for nurturing those who join it.' And so it proved.

We know, further, that the quality of attention which doctors or nurses give to their patients makes a great deal of difference to an individual's experience of illness, and the anxiety and emotional (indeed physical) pain to which this gives rise. There is a substantial scientific literature on the emotional dimensions of health care, from the different research perspectives of information-sharing, emotional labour, and unconscious defences against anxiety. But there is no room for doubt about the central relational issue. Furthermore, although the developments which have taken place in regard to care of the dying, through the hospice movement and its broader extensions, owe a great deal to the pharmaceutical management of pain, its achievements are also due to the recognition of the emotional and relational ambience surrounding patients. Indeed one is inseparably linked to the other, since lack of attention to physical pain is sometimes an effect of an environment in which the patient cannot be seen as a whole person. Such inattention is often a selfdistancing defence against the recognition of pain and suffering.

Of course one could also cite countless more 'exceptional' cases, of the many 


\section{A relational society}

prominent individuals, for example writers and artists, sometimes from obscure and difficult backgrounds, who have attributed the beginning of their creative life and its opportunities to a particular friend or teacher, whose interest in them was the key to their discovering or recognising their potential. Or one could point to the common experience of young people learning to do music, or to act, or to swim, and how much difference the quality of attention from a teacher can make.

This perspective suggests that a significant measure of value, and indeed of the well-being of a society, should lie in the qualities of relationship which are available to individuals at each stage of their life-course. It is not economic growth as it is counted in money terms by which we should measure the progress or improvement in our society, but by the attention given to people and their development. It is surely obvious, furthermore, that as the investment in human labour that is required to produce material goods diminishes, thanks to modern technologies, so the potential availability of human resources for the development and care of persons should increase. There is no conceivable material or technological excuse for unemployment, when there is abundant work which could and should be done, in nurturing, developing and expressing human capabilities.

Nor should this be thought of simply as the substitution of one kind of 'consumption' for another, or a change in the balance between them. Labour invested in human relationships is a form of production - as much as labour invested in the manufacture of commodities. Since it shapes future capacities, it is even more an investment in the future. This is the case for the 'human work' which takes place in schools or day-nurseries, or in training and developing employees, or in looking after the ill, or indeed in the appropriate punishment and care of offenders.

\section{Relations with the material world}

I now want to turn to relationships between humankind and the material world, given that this is currently a deeply problematic area, and one where long-held assumptions of human entitlement and 'common interest' now need to be called into question. The dominant assumption underlying the growth of capitalism has been that the material world - nature - can and should be exploited for human benefit, and that the consequences such exploitation might have for nature itself are of no interest or account. Although the idea that the earth was created for human benefit goes back 


\section{Soundings}

at least as far as Genesis, the cumulative effects of the industrial revolution and now neoliberal globalisation mean that this position is no longer tenable - if it ever was.

The growth of human scientific, technological and productive power has generally been told as a story of triumph - and indeed this is also how it appears in The Communist Manifesto of Marx and Engels.

The bourgeoisie, during its rule of scarce one hundred years, has created more massive and more colossal productive forces than have all preceding generations together. Subjection of nature's forces to man, machinery, application of chemistry to industry and agriculture, steam navigation, railways, electric telegraphs, clearing of whole continents for cultivation, canalisation of rivers, whole populations conjured out of the ground - what earlier century had even a presentiment that such productive forces slumbered in the lap of social labour?

We are now beginning to see things differently. Nature is not an inexhaustible resource, put there by divine providence, merely to serve human purposes. Furthermore, the entire conceptual scheme by which humankind and nature are defined as separate entities can now be seen to be a misleading one. ${ }^{4}$

We tend to understand 'nature' as an entity independent of our consciousness, revealed to us in its true character through the discoveries of science. Thus we imagine that we look through telescopes at the universe rather in the way that we look out of a window at what lies outside it. But in reality our knowledge and understanding of nature is less straightforward than this. What we see, and know, is shaped by what we 'see with', and by the means through which we investigate it.

Bruno Latour has demonstrated that most of what we believe we know about nature is the outcome of highly selective interventions through which aspects of nature have been selected, isolated and practised upon. ${ }^{5}$ These investigations lead to 'findings' - for example the discoveries of bacteria, electricity, DNA, radioactivity, gravitation - which have usually been made in the highly artificial environment of laboratories. It is through such discoveries that our understanding of nature is ordered. There is a considerable 'fit' between the discoveries human beings have made and continue to make - of the entities we learn to perceive and manipulate - and human (not least economic) purposes. The discovery of bacteria enables the 


\section{A relational society}

control of diseases; of electricity the powering of machines and the lighting and heating of dwellings; of gravity the design of bridges, machines and guns; of DNA, sooner or later, the designing of crops and the control of some diseases.

In other words, we inhabit a nature known to us through our deliberate and controlled interactions with it, undertaken from the perspective of our own interests and purposes. A predominantly capitalist society, over several centuries, has given rise to a certain form of knowledge of nature, one of astounding power. And this form of understanding has historically eclipsed others. But, its perspicacity and power notwithstanding, it remains one form of knowledge, one among other possible forms. For example aboriginal peoples see and know a different world, and impute different properties to it. So for that matter did the prescientific civilisations which ordered their world through a religious cosmology. In so far as each of these 'ways of knowing' supports a particular kind of human society, and seems to have been constructed in relation to its particular needs and desires, we may suppose that in some sense each of them was serviceable, or worked, to a certain degree and for certain purposes. Latour has recently made this case in relation to religious practices, arguing that even though they make little sense in relation to a scientific world-view, they may nevertheless be practices that generate meanings that sustain a form of well-being. ${ }^{6}$

The dominant framing of relations between humankind and nature within capitalism defines the natural in a merely instrumental way, supporting the categorisation of 'natural resources' as mere inputs into productive processes - as 'factors of production' - whose value is measured in terms of their contribution to market value ('exchange value', in Marx's terms). Human labour and land are defined in classical economic theory in the same way, their value being reducible to the contribution they make to the production of saleable products.

\section{Non-market values}

Resistance to these definitions has been present throughout the history of market society. Some land is protected from the imperatives of the market - by private owners who may hold its qualities to be 'beyond price', or by public owners who exclude some land from market exchange on grounds of its special value, perhaps because it is part of 'the commons', or because it is especially beautiful, or because of its historical significance. 


\section{Soundings}

Some nineteenth-century critics of industrialism and capitalism (including John Ruskin and William Morris) argued that the relations between humankind and material things embodied in labour had value and significance beyond their profitability. The value of what is produced through craftsmanship - in regard to the object made, its maker and its user - was a special one. They contrasted the expressiveness and beauty of what was made in the pre-industrial era of artisanal production with what came about during the era of industrial manufacture. They held that the social relations of artisan production, through the associations of guilds and the like, were of a morally superior kind than those of factory production, and its products often more beautiful.

The continuing value accorded to the production of works of art, and the widespread levels of aspiration to engage in this and other forms of creative activity, represent an evaluation of the same kind, in which a specific activity is accorded intrinsic value beyond what markets in themselves might accord to it.

Such particularistic, intrinsic, valuations are important in individuals' lives, and perhaps have become more so as material prosperity has become greater. One can think of the cultivation of such activities as cooking, gardening, house-renovation, dancing and music-making as an indication of the high value accorded to human relations with things (or symbolic practices) in contemporary society. These activities are also necessarily social in their nature, reflecting or bringing into existence 'communities of practice' and enjoyment, through which individuals' activities and commitments are supported. But when such activities are celebrated in print, or in programmes on television, it is often unclear whether we are being invited to value an intrinsic commitment, or the material reward which pursuit of this can bring. Does the charisma derive from a leading footballer's talent, or from his unimaginable wealth?

Respect for value-oriented relationships of different kinds (both with people and with things or practices) now exist on the margins of the capitalist economic system, although in a continuing dialogue with it. The defenders of 'intrinsic goods' (like protected landscapes) have to fight to protect them from being invaded and overrun by market forces, which is often to say corporate interests. Artisan producers, or shop-owners, have to find users and purchasers in the market who are willing to pay a premium for the higher value conferred by 'creative' forms of production. Individuals have to carve out time from paid work to engage in activities of authentic value, or to find a balance between work that will pay sufficiently and 


\section{A relational society}

work that they might wish to do.

These alternative moral systems loop around and intersect with each other. The London art market becomes a major earner of foreign exchange for the UK, and Damien Hirst unashamedly celebrates money in his own art work. Who is the winner in these transactions, the value of art or the value of money? Are professional sports, or the Olympic Games, demeaned in their essence by their invasion by commercial sponsors, or does this merely enhance their attraction for performers and audiences? Many successful companies incorporate into their production systems high quality design or research, or an attention to human relationships, in order to signify an attention to values beyond market exchange - even as these are deployed in its service.

The world of individualist, acquisitive capitalism has become unsustainable, for many reasons. Its ideology of individual self-interest violates human needs for connectedness and mutual care. Its unseeing and rapacious attitude to the material environment is threatening to destroy the conditions of life on the planet. Its conception of profit-seeking as the end of life, rather than, as it should be, merely a specific economic device for bringing about economic initiative and efficiency, substitutes means for ends in the organisation of society. Some reconsideration of these mistaken values, and the emergence of countercurrents to them, can already been seen to be taking place. But these arguments need to be taken much further: a substantial rebalancing of social values away from profit-seeking and market imperatives is urgently needed.

This is a slightly different version of Michael Rustin's contribution to After neoliberalism: the Kilburn Manifesto, available at www.soundings.org.uk.

Michael Rustin is a founding editor of Soundings and is co-editor of After neoliberalism: the Kilburn Manifesto.

\section{Notes}

1. This idea that individuals are the outcome of complex social arrangements and relationships was the starting point of the field of sociology: it was the 


\section{Soundings}

grounds for sociology's critique of the 'individualist' disciplines of economics and psychology as descriptions of the ontological foundations of human existence.

2. In IPPR's recent short book The Relational State (G. Cooke and R. Muir (eds), IPPR 2012), its principal author Geoff Mulgan argues that just as the state previously changed from being a coercive to a delivery state, now is the time to move towards the relational state. This argument seems to be a self-critique of New Labour's approach to government, and as such is welcome. But the book focuses its criticism on a top-down, centralising and bureaucratic state (certainly one enemy of a relational society), whereas I would argue that in our time its greater enemy is the ethos of an unfettered corporate capitalism. On this crucial subject The Relational State is silent.

3. P. Townsend, Poverty in the United Kingdom, Penguin 1979.

4. M.J. Rustin, 'How is climate change an issue for psychoanalysis,' in S. Weintrobe (ed) Engaging with Climate Change, Routledge 2013.

5. B. Latour, Science in Action, Harvard University Press 1987; and Politics of Nature, Harvard University Press 2004.

6. B. Latour, On the Modern Culture of the Factish Gods, Duke University Press 2010. 